\title{
The Productivity Model of Horizontal Well Considering Acidification Effect in Anisotropic Reservoirs
}

\author{
Enhui Sun*, Wei Yang, Qin Peng, Peng Meng, Songru Mu \\ Bohai Oilfield Research Institute of CNOOC Ltd. Tianjin Branch, Tianjin, China \\ Email: *sunenh@cnooc.com.cn
}

How to cite this paper: Sun, E.H., Yang, W., Peng, Q., Meng, P. and Mu, S.R. (2020) The Productivity Model of Horizontal Well Considering Acidification Effect in Anisotropic Reservoirs. World Journal of Engineering and Technology, 8, 19-32. https://doi.org/10.4236/wjet.2020.81003

Received: September 3, 2019

Accepted: December 8, 2019

Published: December 11, 2019

Copyright $\odot 2020$ by author(s) and Scientific Research Publishing Inc. This work is licensed under the Creative Commons Attribution International License (CC BY 4.0). http://creativecommons.org/licenses/by/4.0/

\begin{abstract}
When the horizontal well was acidized, in order to predict the productivity, through coordinate transformation method, based on the formation seepage model of horizontal well after acidification, we deduced the formula of horizontal well local skin factor, established the coupling model of reservoir and horizontal wellbore flow, and deduced the semi-analytical productivity model of horizontal well considering the change of local skin factor. Based on the example, the effect of horizontal well length, reservoir anisotropy coefficient, mud damage depth and damage degree on the production-increasing ratio after acidification were studied. The results showed reservoir with greater anisotropy, serious wellbore pollution and deeper mud invasion near wellbore, and that the stimulation effect of horizontal well after acidification was better.
\end{abstract}

\section{Keywords}

Anisotropy, Acidification Effect, Coordinate Transformation, Skin Factor, Productivity of Horizontal Well

\section{Introduction}

While the horizontal well was produced, its productivity cannot reach the intended purpose, the reason partly is the formation near the horizontal well was damaged in the process of drilling and completion [1]. Acidification is an important measure for eliminating formation damage, so it can improve the well productivity. At present, some scholars have done some studies about the productivity of horizontal well [2]-[9], but it is not suitable for predicting that the productivity of well after reservoirs was acidized. Liu Zuhe [10] combined with simplifying three-dimensional flow model of Bosiov horizontal well, used hy- 
droelectric similarity principle and equivalent seepage resistance method, established productivity after acidification. Yuan Lin [11] referred to conventionally the productivity formula of horizontal well, simplified the three-dimensional seepage of horizontal well into two-dimensional plane seepage, deduced the productivity formula of horizontal well after acidification. Based on the previous research, we used coordinate transformation method, deduced the formula for calculating the horizontal well skin factor, and deduced the semi-analytical productivity model considering acidification, analyzed the model with actual data.

\section{The Skin Factor Model of Horizontal Well after Acidification}

In order to accurately calculation the horizontal well skin factor after acidification, it is necessary to understand the seepage model of acidification formation. The study in document [12] shows that the flow of acid is elliptical radial divergence during acidification for homogeneous anisotropic formation, so the isobaric line of the area near the wellbore after acidized is a cluster of ellipses. A hypothetical horizontal well seepage model after acidification is given, as shown in Figure 1.

\subsection{The Skin Factor When Acidification Radius Is Greater than Pollution Zone Radius}

When acidification radius is greater than or equal to pollution zone radius $\left(r_{\mathrm{a}} \geq r_{\mathrm{d}}\right)$, pollution zone is improved by acidification, the acidification zone become a new "pollution zone". The radius of acidification zone becomes new radius of "pollution zone", the permeability of acidification zone becomes a new permeability of "pollution zone".

Therefore, according to the hypothesis in reference [13], the skin factor in section $x$ of horizontal well is expressed as follows:

$$
S_{\mathrm{a}}(x)=\left(K / K_{\mathrm{a}}\right) \ln \left[\frac{1}{\beta+1}\left(\frac{r_{\mathrm{ah}}(x)}{r_{\mathrm{w}}}+\sqrt{\frac{r_{\mathrm{ah}}^{2}(x)}{r_{\mathrm{w}}^{2}}+\beta^{2}+1}\right)\right]
$$

$S_{\mathrm{a}}(x)$ is local skin factor, $f K$ is reservoir permeability, $\mathrm{mD} ; K_{\mathrm{a}}$ is acidification zone permeability, $\mathrm{mD} ; r_{\mathrm{ah}}(x)$ is the distance of horizontal well heel in acidification zone, $\mathrm{m} ; \beta$ is reservoir anisotropy coefficient, $f, r_{\mathrm{w}}$ is wellbore radius, $m$.

\subsection{The Skin Factor When Acidification Radius Is Less than Pollution Zone Radius}

When acidification radius is less than pollution zone radius $\left(r_{\mathrm{a}}<r_{\mathrm{d}}\right)$, acids does not penetrate the whole pollution zone. In the original polluted zone, formed a composite zone consisting of acidification zone and polluted zone.

On the $y z$ plane, the horizontal well can be regarded as the vertical well with radius $r_{\mathrm{w}}$ in a reservoir with thickness $L$, considering reservoir anisotropy, the steady seepage equation on $y z$ plane is as follows: 


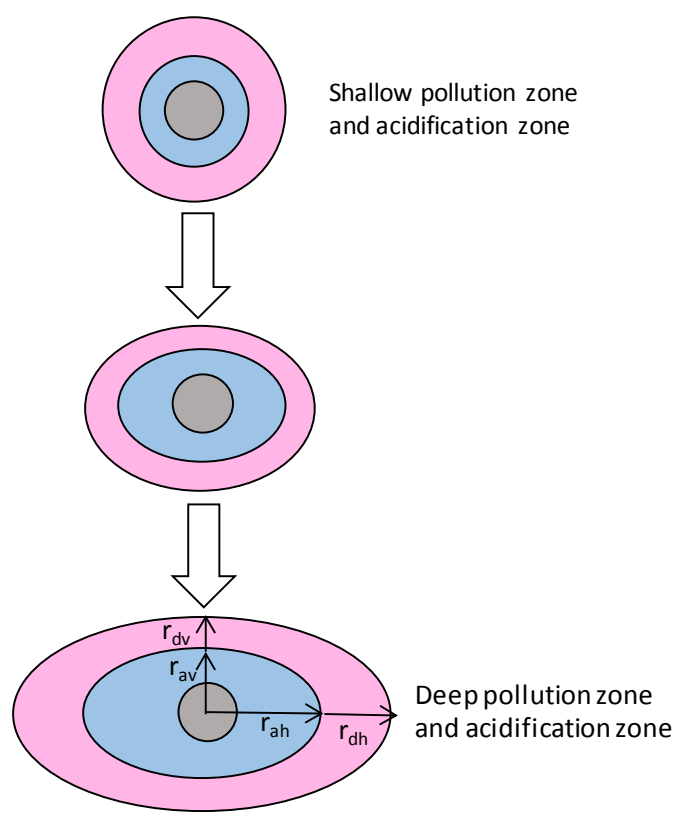

Figure 1. The diagram of vertical plane seepage model for horizontal well after acidification.

$$
K_{z} \frac{\partial^{2} P}{\partial z^{2}}+K_{y} \frac{\partial^{2} P}{\partial y^{2}}=0
$$

The internal boundary condition is:

$$
\sqrt{z^{2}+y^{2}}=r_{w} ; P^{2}=P_{w f}^{2}
$$

On the $y z$ plane, the isobaric lines around the wellbore were concentric ellipses, $u v$ coordinate system was introduced, the isobars around the wellbore become confocal concentric ellipses, as shown in Figure 2.

Introduced $u v$ coordinate system, and conversed coordinate, there are:

$$
u=\left(K_{y} / K_{z}\right)^{1 / 4} z ; v=\left(K_{z} / K_{y}\right)^{1 / 4} y
$$

Formula (2) can be changed to:

$$
\frac{\partial^{2} P}{\partial u^{2}}+\frac{\partial^{2} P}{\partial v^{2}}=0
$$

Formula (3) can be changed to:

$$
\left(K_{z} / K_{y}\right)^{1 / 4} u^{2}+\left(K_{y} / K_{z}\right) v^{2}=r_{w}^{2} ; P^{2}=P_{w f}^{2}
$$

In order to solve the above Laplace equation with elliptic inner boundary conditions, conformal transformation is introduced to transform the elliptic coordinate system into the $\rho \theta$ coordinate system, there are:

$$
u=b \cosh \rho \cos \theta ; v=b \sinh \rho \sin \theta
$$

When $\rho=\rho_{w}$ at the wellbore, derived from Equation (7):

$$
\frac{u^{2}}{b^{2} \cosh ^{2} \rho_{w}}+\frac{v^{2}}{b^{2} \sinh ^{2} \rho_{w}}=1
$$




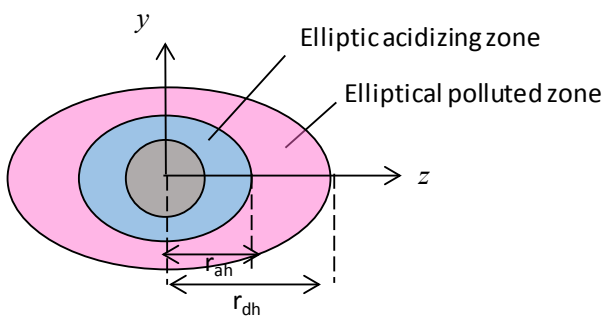

Original coordinate system (yz plane )

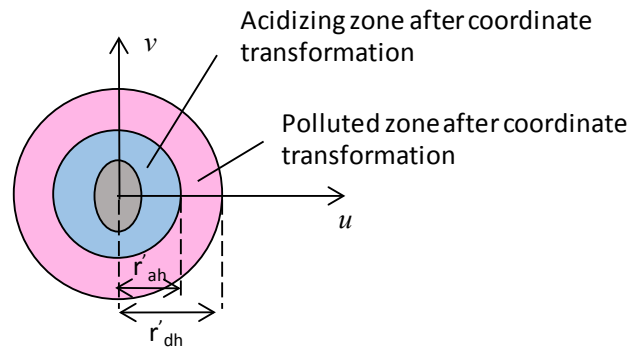

Conversion coordinate system

(uv plane)

Figure 2. The diagram of polluted zone and acidification zone of coordinate transformation.

Comparison formula (5) and formula (7), there are:

$$
\tanh ^{2} \rho_{w}=K_{z} / K_{y} ; b^{2}=r_{w}^{2}\left(K_{y}-K_{z}\right) /\left(K_{z} K_{y}\right)^{1 / 2}
$$

The average radius of the elliptical isobars can be defined as the average of the long and the short axes, there are:

$$
\bar{r}=\frac{a \cosh \rho+a \sinh \rho}{2}=\frac{b}{2} \mathrm{e}^{\rho}
$$

After coordinate transformation, as long as the average radius of the wellbore and the average radius of the reservoir damage zone are calculated separately, it can be solved by using the formula of skin factor calculation.

Comparison formula (9) and formula (10), the average radius of wellbore is:

$$
\overline{r_{w}}=\frac{b}{2} \mathrm{e}^{\rho_{w}}=r_{w}\left(\sqrt{K_{y} / K_{z}}+1\right) / 2\left(K_{y} / K_{z}\right)^{1 / 4}
$$

The anisotropic problem is transformed into isotropic problem by coordinate transformation. Where the anisotropic coefficient $\beta=\sqrt{K_{y} / K_{z}}$, then formula (11) becomes:

$$
\overline{r_{w}}=r_{w}(\beta+1) / 2 \sqrt{\beta}
$$

Formula (4) can be changed to:

$$
u=\sqrt{\beta} z ; v=y / \sqrt{\beta}
$$

The long and short axes of isobaric lines in equivalent isotropic formations are obtained from Equation (7) respectively:

$$
u_{o}=b \cosh \rho ; v_{o}=b \sinh \rho
$$


For the elliptical polluted zone, combination formula (13) and formula (14), when $\rho=\rho_{\mathrm{d}}$, as follows:

$$
\rho_{\mathrm{d}}=\sinh ^{-1}\left(v_{\mathrm{d}} / b\right)=\sinh ^{-1}\left(r_{\mathrm{dh}} / b \sqrt{\beta}\right)
$$

Combination formula (10) and formula (15), average radius of elliptical polluted zone is:

$$
\overline{r_{\mathrm{d}, \mathrm{eq}}}=\frac{b}{2} \mathrm{e}^{\rho_{\mathrm{d}}}=\frac{r_{w}}{2} \sqrt{\beta-1 / \beta}\left[\left(\frac{r_{\mathrm{dh}}}{r_{w} \sqrt{\beta^{2}-1}}\right)^{2}+1\right]
$$

Formation permeability $K$ and composite zone permeability $K_{\mathrm{da}}$ are defined. The expression of anisotropic formation skin factor derived from reference [14] is used:

$$
S_{\mathrm{d}}=\left(K / K_{\mathrm{da}}\right) \ln \left(\overline{r_{\mathrm{d}, \mathrm{eq}}} / \overline{r_{w}}\right)
$$

Combination formula (12) formula (16) and formula (17), skin factor of horizontal well is:

$$
S_{\mathrm{d}}=\left(K / K_{\mathrm{da}}\right) \ln \left[\frac{1}{\beta+1}\left(\frac{r_{\mathrm{dh}}}{r_{w}}+\sqrt{\frac{r_{\mathrm{dh}}^{2}}{r_{\mathrm{w}}^{2}}+\beta^{2}-1}\right)\right]
$$

$K_{\mathrm{da}}$ of composite zone is obtained by average of radial flow permeability in reference [15]:

$$
K_{\mathrm{da}}=\frac{\ln \left(r_{\mathrm{dh}} / r_{\mathrm{w}}\right)}{\left(1 / K_{\mathrm{d}}\right) \ln \left(r_{\mathrm{dh}} / r_{\mathrm{ah}}\right)+\left(1 / K_{\mathrm{a}}\right) \ln \left(r_{\mathrm{ah}} / r_{\mathrm{w}}\right)}
$$

In document [16], the radius of polluted zone and acidification zone distributes heterogeneous along the horizontal well section, and the permeability of polluted zone and acidification zone are constant, as shown in Figure 3. The radius of polluted zone and acidification zone are functions of the distance form horizontal well heel $x, r_{\mathrm{dh}}=r_{\mathrm{dh}}(x), r_{\mathrm{ah}}=r_{\mathrm{ah}}(x)$.

Formula (19) can be changed to:

$$
K_{\text {da }}(x)=\frac{\ln \left[r_{\text {dh }}(x) / r_{\mathrm{w}}\right]}{\left(1 / K_{\mathrm{d}}\right) \ln \left[r_{\mathrm{dh}}(x) / r_{\mathrm{ah}}(x)\right]+\left(1 / K_{\mathrm{a}}\right) \ln \left[r_{\mathrm{ah}}(x) / r_{\mathrm{w}}\right]}
$$

Formula (18) can be changed to:

$$
S_{\mathrm{d}}(x)=\left[K / K_{\mathrm{da}}(x)\right] \ln \left[\frac{1}{\beta+1}\left(\frac{r_{\mathrm{dh}}(x)}{r_{w}}+\sqrt{\frac{r_{\mathrm{dh}}^{2}(x)}{r_{\mathrm{w}}^{2}}+\beta^{2}+1}\right)\right]
$$

$S_{\mathrm{d}}(x)$ is reservoir skin factor, $f, K$ is reservoir permeability, $\mathrm{mD} ; K_{\mathrm{da}}$ is permeability in composite zone, $\mathrm{mD} ; r_{\mathrm{ah}}(x)$ is radius of pollution zone, $m ; \beta$ is reservoir anisotropy coefficient, $f ; r_{\mathrm{w}}$ is wellbore radius, $m$.

In reference [13], while the horizontal well was polluted, the heel of horizontal well is the greatest, the toe is the smallest. From the heel to the toe, the radius of the pollution zone varies linearly. Based on previous studies, the author 


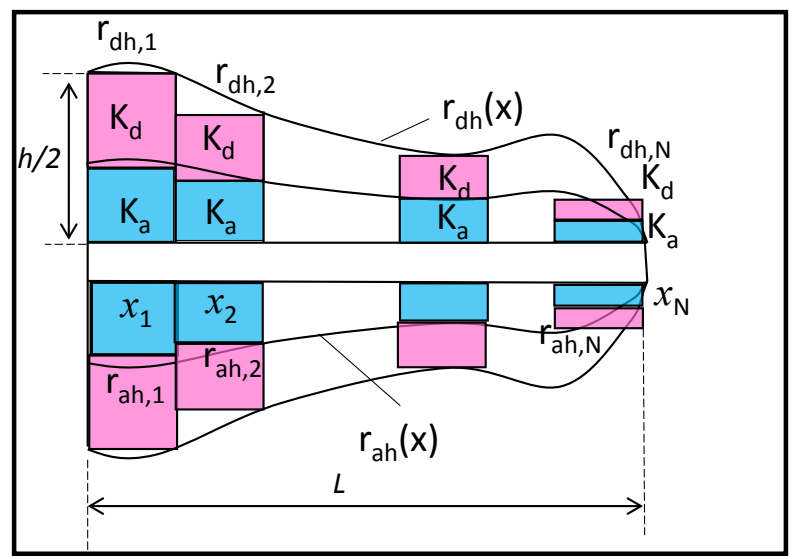

Figure 3. The wellbore distribution model of polluted zone and acidification zone.

assumed that the acidification zone and polluted zone radius $d$ is tribute parabolically along the wellbore. Because the contact time between the toe of horizontal well and acid fluid is relatively short, it can be assumed that the formation is not polluted. When the radius of acidification zone reaches the maximum, the distribution functions of the radius of pollution zone and acidification zone along the wellbore direction are as follows:

$$
\begin{gathered}
r_{\mathrm{dh}}(x)=-\frac{R_{\mathrm{m}, \text { max }}}{L^{2}} x^{2}+R_{\mathrm{m}, \text { max }}+r_{w} \\
r_{\mathrm{ah}}(x)=-\frac{R_{\mathrm{f}, \text { max }}}{L^{2}} x^{2}+R_{\mathrm{f}, \text { max }}+r_{w}
\end{gathered}
$$

$R_{\mathrm{m}, \max }$ is maximum depth pollution invasion, $m ; R_{\mathrm{f}, \max }$ is maximum depth acid invasion, $m$; $L$ is horizontal well length, $\mathrm{m}$.

Combination formula (20) formula (22) formula (23) and formula (21), the distribution pattern of local epidermal factors after acidification of horizontal well can be obtained.

\section{The Productivity Model Considering Skin Factor after Acidification}

From the toe to the heel of horizontal wellbore, the mass flow rate of fluid increased gradually. There is a coupling relationship between seepage flow in reservoir and in horizontal wellbore [17].

\subsection{The Seepage Model of Near Well Zone in Production Section of Horizontal Well}

Assumed that the upper and lower boundaries of the reservoir were closed, $Z_{\mathrm{w}}$ is the distance between the horizontal well and the lower boundaries of the reservoir, the horizontal section is divided into $N$ micro-segments along the length direction, and the micro-lines on the micro-segments converge radially and uniformly, while the radial flow $q_{r}(i)$ of micro-segments is different. 
According to the mirror reflection principle, the micro-element of the production section in section $i(1 \ll i \ll N)$ is transformed into the production well row in the infinite formation. From the potential superposition principle, the potential of the micro-element section in section $i$ in the boundary reservoir at any point $M(x, y, z)$ in space can be obtained as follows:

$$
\Phi_{i}(x, y, z)=\Phi_{e}-\frac{1}{4 \pi} \sum_{i=1}^{N}\left[q_{r}(i)\left(\varphi_{i}-\varphi_{e i}\right)\right]
$$

Among, $\Phi_{i}$ is potential of section $i$ at any point in the reservoir, $q_{r}(i)$ is flow of in section $i, \Phi_{e}$ is potential at the boundary.

$$
\begin{gathered}
\varphi_{i}=\zeta_{i}\left(z_{w}, x, y, z\right)+\zeta_{i}\left(-z_{w}, x, y, z\right)+\sum_{n=1}^{\infty}\left[\zeta_{i}\left(2 n h+z_{w}, x, y, z\right)\right. \\
+\zeta_{i}\left(-2 n h+z_{w}, x, y, z\right)+\zeta_{i}\left(2 n h-z_{w}, x, y, z\right) \\
\left.+\zeta_{i}\left(-2 n h-z_{w}, x, y, z\right)-\frac{2 L}{n N h}\right]+C_{i} \\
\text { Among: } \zeta_{i}\left(\varepsilon_{i}, x, y, z\right)=\ln \frac{r_{i 1}+r_{i 2}+\frac{L}{N}}{r_{i 1}+r_{i 2}+\frac{L}{N}} ; \\
r_{i 1}=\sqrt{\left[(i-1) \frac{L}{N}-x\right]^{2}+y^{2}+\left(\varepsilon_{i}-z\right)^{2}} \\
r_{i 2}=\sqrt{\left[i \frac{L}{N}-x\right]^{2}+y^{2}+\left(\varepsilon_{i}-z\right)^{2}}
\end{gathered}
$$

The pressure of boundary is $p_{e}$, the flow pressure at the heel of horizontal well is $p_{h f}$, the pressure at the midpoint of section $i$ is $p_{w f}(i)$, and the potential at the midpoint of section $j(1 \ll j \ll N)$ is $\Phi_{i j}$, the relationship between the radial flow rate $q_{r}(i)$ and the flow pressure $p_{w f}(i)$. The horizontal well seepage model as follows:

$$
\begin{gathered}
{\left[\begin{array}{ccccc}
\varphi_{11}-\varphi_{e 1} & \varphi_{12}-\varphi_{e 2} & \varphi_{13}-\varphi_{e 3} & \cdots & \varphi_{1 N}-\varphi_{e N} \\
\varphi_{21}-\varphi_{e 1} & \varphi_{22}-\varphi_{e 2} & \varphi_{23}-\varphi_{e 3} & \cdots & \varphi_{2 N}-\varphi_{e N} \\
\varphi_{31}-\varphi_{e 1} & \varphi_{32}-\varphi_{e 2} & \varphi_{33}-\varphi_{e 3} & \cdots & \varphi_{3 N}-\varphi_{e N} \\
\vdots & \vdots & \vdots & \ddots & \vdots \\
\varphi_{N 1}-\varphi_{e 1} & \varphi_{N 2}-\varphi_{e 2} & \varphi_{N 3}-\varphi_{e 3} & \cdots & \varphi_{N N}-\varphi_{e N}
\end{array}\right]\left[\begin{array}{c}
q_{r}(1) \\
q_{r}(2) \\
q_{r}(3) \\
\vdots \\
q_{r}(N)
\end{array}\right]} \\
=\frac{4 \pi K}{\mu_{o}}\left[\begin{array}{c}
p_{e}-p_{w f}(1)+\rho g\left(z_{e}-z_{w}\right) \\
p_{e}-p_{w f}(2)+\rho g\left(z_{e}-z_{w}\right) \\
p_{e}-p_{w f}(3)+\rho g\left(z_{e}-z_{w}\right) \\
\vdots \\
p_{e}-p_{w f}(N)+\rho g\left(z_{e}-z_{w}\right)
\end{array}\right]
\end{gathered}
$$

Among, $p_{e}$ is the pressure of boundary, MPa; $q_{r}(i)$ is flow of in section $i$, $\mathrm{m}^{3} / \mathrm{s} ; \quad p_{w f}(i)$ is the pressure at the midpoint of section $i, \mathrm{MPa} ; K$ is reservoir permeability, $\mathrm{mD} ; \mu_{o}$ is oil viscosity, mPa.s; $\rho$ is oil density, $\mathrm{kg} / \mathrm{m}^{3} ; z_{w}$ is the distance between horizontal well and lower boundary of reservoir, $\mathrm{m} ; z_{e}$ is 
the distance between upper and lower boundary of the reservoir

\subsection{Wellbore Flow Model after Acidification}

Assumed the flow in horizontal wellbore was single-phase incompressible fluid without gravity loss. The pressure loss of the $i$ section in the production section were $\Delta p_{w}(i)$, includes friction loss $\Delta p_{f}(i)$ caused by wellbore wall, acceleration loss $\Delta p_{a}(i)$ caused by radial inflow of fluid, additional pressure drop $\Delta p_{s}(i)$ caused by skin factor:

$$
\Delta p_{w}(i)=\Delta p_{f}(i)+\Delta p_{a}(i)+\Delta p_{s}(i)
$$

The friction loss $\Delta p_{f}(i)$ is:

$$
\Delta p_{f}(i)=10^{-6} \frac{2 \rho L}{\pi^{2} N D^{5}} c_{f} f_{w}(i)\left[Q(i)+\frac{q_{r}(i)}{2}\right]^{2}
$$

Among, $\Delta p_{f}(i)$ is friction loss of $i$ section, MPa; $D$ is wellbore diameter, $m$; $Q(i)$ is upstream flow of the $i$ section, $\mathrm{m}^{3} / \mathrm{s} ; q_{r}(i)$ is radial inflow of the $i$ section, $\mathrm{m}^{3} / \mathrm{s} ; \rho$ is oil density, $\mathrm{kg} / \mathrm{m}^{3} ; c_{f}$ is correction coefficient considering the effect of radial inflow, $f ; f_{w}(i)$ is wellbore friction coefficient, when the wellbore flow is laminar flow, when $R_{e}(i)<2300, f_{w}(i)=\frac{16\left(1+0.43 R_{e w}^{0.612}\right)}{R_{e}(i)}$, Among, $R_{e w}$ is Re of wellbore inflow, dimension; When the wellbore flow is turbulent, $R_{e}(i)>2300, f_{w}(i)=\left\{-4.0 \log \left[\frac{\varepsilon}{3.7 D}+\frac{1.255}{R_{e}(i)}\right]\right\}\left(1-0.0153 R_{e w}^{0.3978}\right)$, Among, $\varepsilon$ is absolute roughness of wellbore, $m$.

The acceleration loss $\Delta p_{a}(i)$ is:

$$
\Delta p_{a}(i)=10^{-6} \frac{16 \rho q_{r}(i)}{\pi^{2} D^{4}}\left[2 Q(i)+q_{r}(i)\right]
$$

Selected the segment $\Delta x$ from distance the heel of horizontal well, the additional pressure drop caused by skin factor is $\Delta p_{s}(x)$, the flow rate of radial flow into wellbore is $q_{r}(x)$, so the formula for calculating the additional pressure drop caused by skin factor is defined as follows:

$$
\Delta p_{s}(i)= \begin{cases}10^{-6} \frac{21.3 N q_{r}(i)}{K L} S_{\mathrm{a}}(i) & r_{a} \geq r_{d} \\ 10^{-6} \frac{21.3 N q_{r}(i)}{K L} S_{\mathrm{d}}(i) & r_{a}<r_{d}\end{cases}
$$

Among, $\Delta p_{s}(x)$ is the additional pressure drop caused by skin factor, $\mathrm{MPa}$; $q_{r}(x)$ is the flow rate of reservoir fluid flowing radially into the micro-element section $\Delta x, \mathrm{~m}^{3} / \mathrm{d} ; K$ is the formation permeability, $\mathrm{mD}$.

Combination formula (26) formula (27) formula (29), the pressure loss analysis model of the micro-element section considering the change of skin factor can be obtained: 


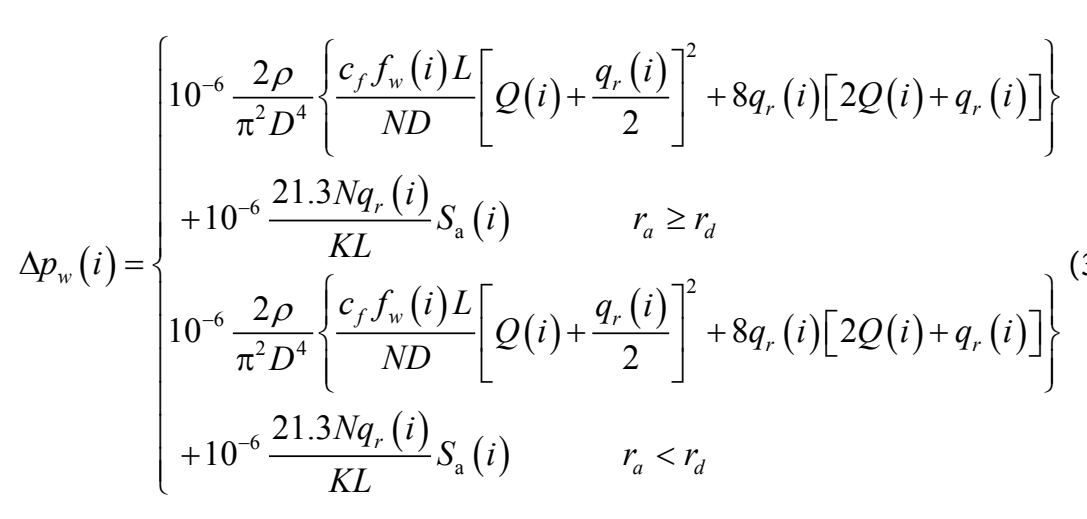

\subsection{Horizontal Well Productivity Model Considering Skin Factor}

For production section of horizontal well, there are the following relationships between flow rate and flow pressure:

$$
p_{w f}(i+1)=p_{w f}(i)+0.5\left[\Delta p_{w}(i)+\Delta p_{w}(i+1)\right] ; \quad Q(i)=\sum_{k=i+1}^{N} q_{r}(k)
$$

Among, $\Delta p_{w}(0)=0 ; p_{w f}(0)=p_{h f}, \quad p_{h f}$ is flow pressure at heel of production section, $Q(N)=0$.

Formula (25) formula (30) and formula (31) constitute a closed system of equations containing $2 N$ equations and $2 N$ unknown variables $\left(q_{r}(i), p_{w f}(i)\right.$ $(1 \ll i \ll N))$. It is horizontal well productivity model considering skin factor in the horizontal section after acidification.

\section{Solution of Semi-Analytical Productivity Model for Horizontal Well}

In the above productivity model, both $q_{r}(i)$ and $p_{w f}(i)$ were unknown, which can be solved by iterative method. Assumed a set of $p_{w f}(i)$ values, $q_{r}(i)$ is solved by formula (25), then $q_{r}(i)$ was replaced by formula (30) and formula (31), and then $q_{r}(i)$ was updated by formula (25), so that the calculation of $q_{r}(i)$ and $p_{w f}(i)$ is reached. Finally, the productivity of horizontal well was obtained.

\section{The Calculation and Analysis of Affect Acidification Effect of Horizontal Well}

\subsection{The Calculation of Example}

The basic parameters of a horizontal well were as follows: horizontal length $L=300 \mathrm{~m}$, wellbore radius $r_{w}=0.1 \mathrm{~m}$, reservoir thickness $h=10 \mathrm{~m}$, formation permeability $K_{h}=0.5 \mathrm{mD}$, pollution zone permeability $K_{\mathrm{d}}=0.1 \mathrm{mD}$, acidification zone permeability $K_{\mathrm{a}}=0.7 \mathrm{mD}$, formation anisotropy coefficient $\beta=3$, oil viscosity $\mu=30 \mathrm{mPa} \cdot \mathrm{s}$, oil density $\rho=840 \mathrm{~kg} / \mathrm{m}^{3}$, oil volume coefficient $B_{o}=1.058$, the pressure at boundary $p_{e}=13 \mathrm{MPa}$, bottom flow pressure $p_{h f}=11 \mathrm{MPa}$, oil release radius $r_{e h}=500 \mathrm{~m}$, maximum mud invasion distance $R_{\mathrm{m}, \max }=1.6 \mathrm{~m}$, maximum acid action distance $R_{\mathrm{f}, \max }=1.0 \mathrm{~m}$.

Used the formula (21) of the skin factor obtained in this paper, combined with 
the actual data above, the fig of the distribution of the skin factor can be drawn (Figure 4).

It can be seen from Figure 4 that the 1 skin factor of horizontal well decreases gradually from heel $(x=0 \mathrm{~m})$ to toe $(x=200 \mathrm{~m})$ after acidification, and the skin factor is less after acidification than the skin factor before acidification. It shows that formation damage near wellbore is removed by acidification method, and the skin factor was reduced, achieved the goal of increase the well productivity.

\subsection{Analysis of Factors of Acidification Effect in Horizontal Well}

Yield multiplier ratio was usually used to evaluate the acidification effect. The yield increase ratio is the ratio of the yield after acidification to that before acidification. According to the calculation results of the previous productivity model, analyzed the factors affecting the acidification effect of horizontal well.

1) Effect of horizontal well length on yield multiplier ratio of horizontal well

Considered the horizontal well length $L=100 \mathrm{~m}, 200 \mathrm{~m}, 300 \mathrm{~m}, 400 \mathrm{~m}, 500 \mathrm{~m}$, other parameters in the above examples. The productivity model proposed in this paper is used to calculate yield multiplier ratio of horizontal well. Figure 5 is the relationship curve of the influence of different horizontal section length on the productivity increase ratio after acidizing. As can be seen from Fig, during the increase of horizontal well length, yield multiplier ratio decreases gradually, and the decreasing range tends to be stable. This shows that the shorter the length of horizontal, the better the acidification effect.

2) Effect of reservoir anisotropy coefficient on yield multiplier ratio of horizontal well

Considered the reservoir anisotropy coefficient $\beta=1,3,5,7,9$ and other parameters in the above examples, used the productivity model proposed in this paper to yield increase ratio of horizontal well. Figure 6 is the relationship curve of the influence of reservoir anisotropy coefficient on yield multiplier ratio of

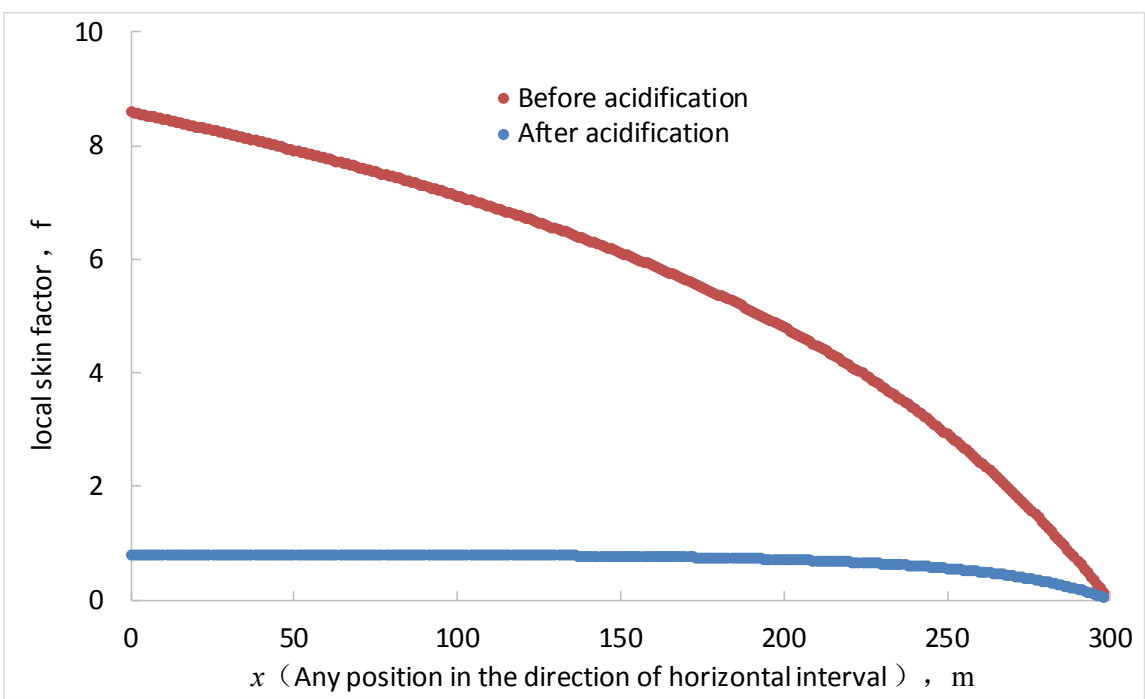

Figure 4. The horizontal segment distribution model of horizontal segment skin factor. 


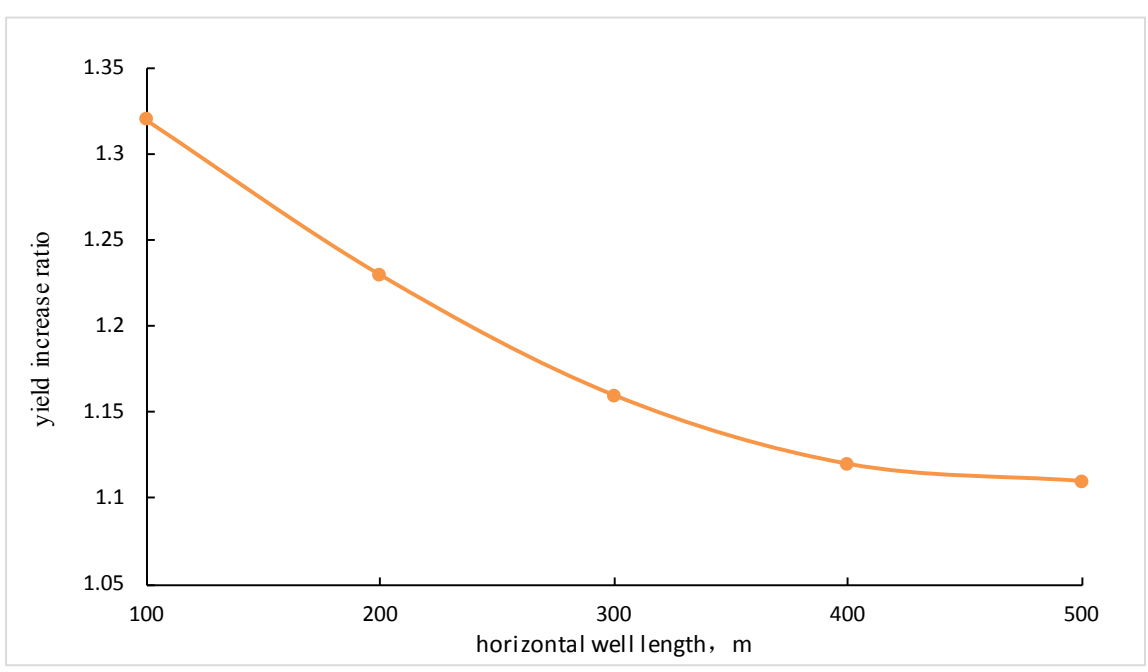

Figure 5. Influence of the length of horizontal well on the effect of yield multiplier ratio after acidification.

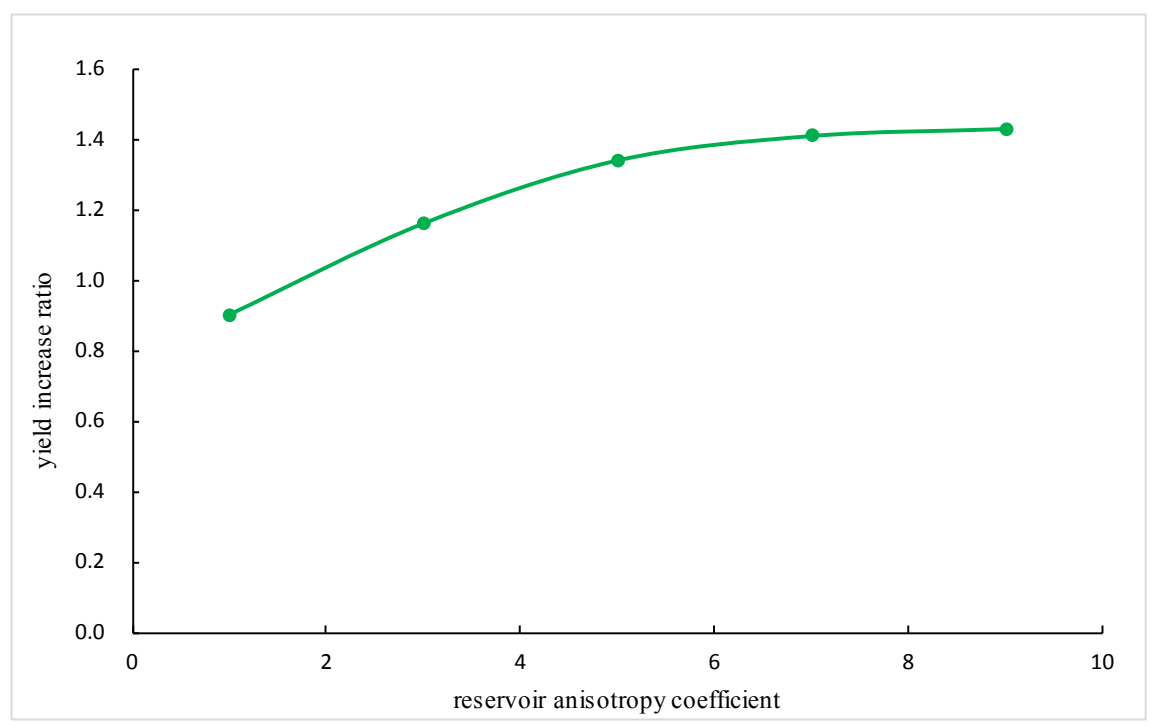

Figure 6. Influence of the reservoir anisotropy on the effect of yield multiplier ratio after acidification.

horizontal well. As can be seen from Figure 6, when other parameters are certain, during the increase of reservoir anisotropy ratio, the yield multiplier ratio is also increasing. This shows that the more serious the formation anisotropy, the better the acidification effect of horizontal well.

3) Effect of pollution depth on yield multiplier ratio of horizontal well after acidification

Considered pollution depth (maximum pollution depth of mud) $R_{\mathrm{m}, \max }=1 \mathrm{~m}$, $1.6 \mathrm{~m}, 2 \mathrm{~m}, 2.4 \mathrm{~m}, 2.8 \mathrm{~m}$, and other parameters as the parameters of the above examples. The effect of maximum pollution depth of mud on the yield increase ratio after acidification is shown in Figure 7. As can be seen from Figure 7, when other parameters are certain, the yield increase ratio of acidification 


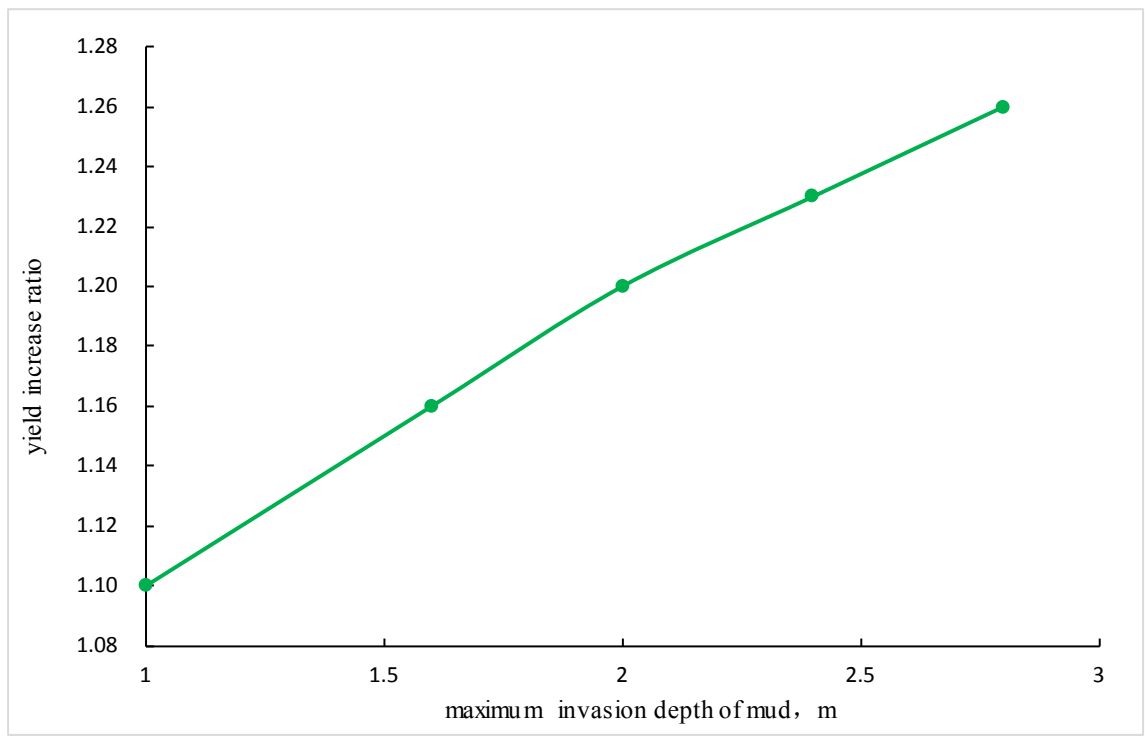

Figure 7. Influence of the maximum invasion depth of mud on the effect of yield multiplier ratio after acidification.

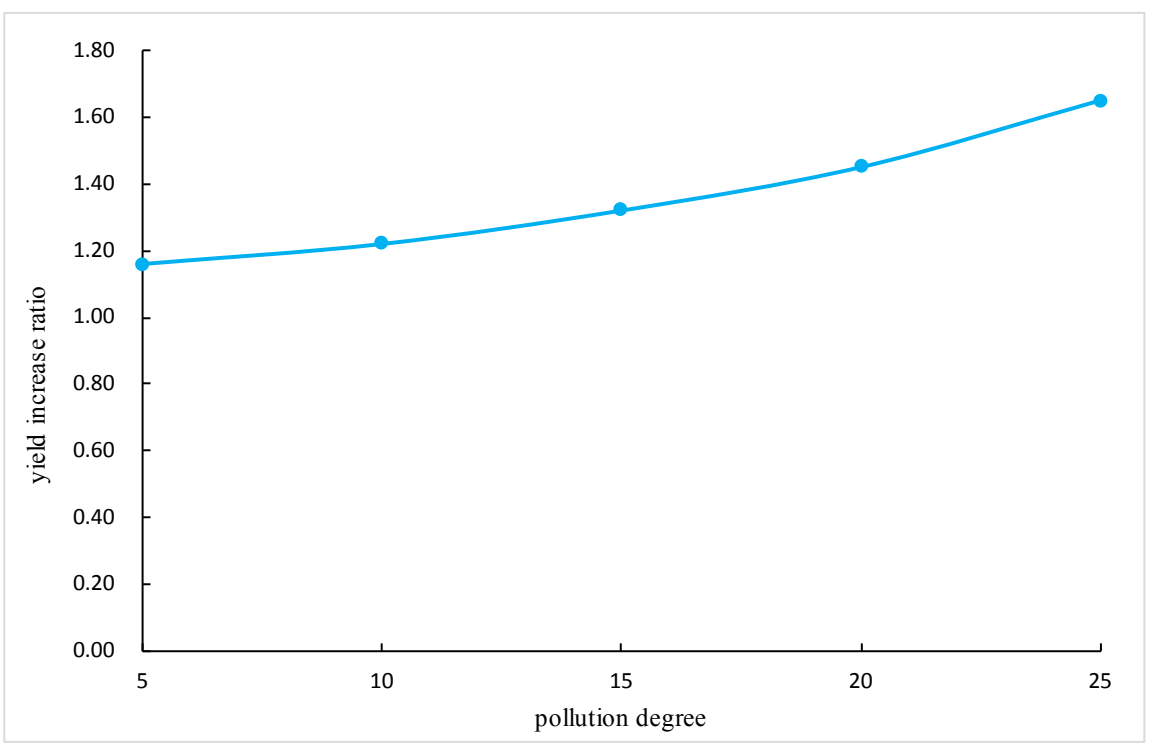

Figure 8. Influence of the pollution degree on the effect of yield multiplier ratio after acidification.

increases with the increase of pollution depth. This shows that the deeper the mud invasion near the wellbore, the better the effect of acidification on increasing production.

4) Effect of pollution degree on yield multiplier ratio of horizontal well after acidification

Considered the damage degree (the formation permeability/polluted area permeability) as $5,10,15,20,25$, and other parameters as the parameters of the above examples, Figure 8 shows the effect of different damage degree on the yield increase ratio of horizontal well after acidification. As can be seen from 
Figure 8, when other parameters are given, the higher the degree of pollution, the greater the ratio of yield increase of acidification. It shows that the acidification effect of horizontal wells is better when the pollution of horizontal wells is more serious. The more serious the pollution around the wellbore, the better the effect of acidification stimulation is, which is also the reason why acidification stimulation is used in the development of oil and gas fields.

\section{Conclusions}

1) Used coordinate transformation, the formula of local skin factor after acidification of horizontal well is obtained when the acidification radius is less than the radius of pollution zone. Combined with the coupled flow model of production section, a semi-analytical productivity model of horizontal well considering the change of local skin factor of acidification effect is derived.

2) Examples show that horizontal well length, formation anisotropy coefficient, mud pollution depth and pollution degree are the main factors affecting the yield increase ratio after acidification.

3) The more anisotropic, serious wellbore pollution and mud invasion near wellbore, the better acidification effect will be.

\section{Conflicts of Interest}

The authors declare no conflicts of interest regarding the publication of this paper.

\section{References}

[1] Wang, F.H., Wang, R.H., Yu, L., et al. (2010) Study on Formation Damage Mechanism of Solid Particles. Fault-Block Oil \& Gas Field, 17, 105-108.

[2] Fan, Z.F. (1993) Study on Productivity Formula of Horizontal Well in Bottom Water Drive Reservoir. Fetroleum Exploration and Development, 20, 71-75.

[3] Guo, X., Chen, L.Y. and Du, Z.M. (2003) Discussion on the Productivity Formula of Joshi Horizontal Well. Journal of Southwest Petroleum Institute, 25, 41-43.

[4] Chen, Y.Q. (2008) Derivation and Comparison of Production Formula for Horizontal Wells. Xinjiang Petroleum Geology, 29, 68-71.

[5] Liu, Z.X., Wang, Y.R., Huang, K., et al. (2009) The Joshi Formula Considering the Friction Loss of Wellbore. Fault-Block Oil \& Gas Field, 16, 94-96.

[6] Chen, X.F., Le, P., Su, G.F., et al. (2010) A New Formula to Calculation the Deliverability of Horizontal Well. Journal of Southwest Petroleum University (Science \& Technology Edition), 32, 93-96.

[7] Meng, Q., Huang, B.G., Wang, N.T., et al. (2013) A New Method for Predicting Horizontal Well Productivity. Fault-Block Oil \& Gas Field, 20, 740-743.

[8] Wang, Y.N., Li, H., Cao, S.H., et al. (2016) Horizontal Well Productivity Calculation and Parameters Considering Wellbore Friction in Bottom Water Reservoir. Fault-Block Oil \& Gas Field, 23, 371-374.

[9] Huang, W.S. (2018) Productivity Formula for Horizontal Well of Top-Bottom Closed Reservoir Based on Re-Splitting Flow Field. Fault-Block Oil \& Gas Field, 25, 66-69. 
[10] Liu, Z.H. (2009) Productivity Analysis of Horizontal Well after Acidification. Inner Mongolia Petrochemical Industry, 15, 27-29.

[11] Yuan, L. and Li, X.P. (2014) Deduction and Application of Productivity Formula of Horizontal Wells after Acidizing. Lithologic Reservoirs, 26, 127-130.

[12] Frick, T. and Economides, M.J. (1991) Horizontal Well Damages Characterization and Removal. SPE 21795.

[13] Furui, K., Zhu, D. and Hill, A.D. (2003) A Rigorous Formation Damage Skin Factor and Reservoir Inflow Model for a Horizontal Well. SPE 84964. https://doi.org/10.2118/74698-MS

[14] Li, C.L. (2006) Reservoir Engineering Principle. Petroleum Industry Press, Beijing, 343-344.

[15] He, G.S. and Tang, H. (2011) Reservoir Physics. Petroleum Industry Press, Beijing, 49-51.

[16] Li, N.Y. and Zhao, L.Q. (2008) Study on Acidizing Damage Characteristics of Horizontal Wells. Petroleum Geology and Engineering, 22, 92-94.

[17] Liu, X.P., Guo, C.Z., Jiang, Z.X., et al. (1999) Coupling Model of Seepage and Horizontal Wellbore Flow in Reservoir. Journal of Petroleum, 20, 82-86. 